\title{
Implementation of Project Management Concept for Conversion into a Smart City: A Case Study on Agartala
}

Swarup Paul ( $\square$ pswarup2008@gmail.com )

National Institute of Technology Agartala https://orcid.org/0000-0003-2261-5818

\section{Research Article}

Keywords: Smart city, Project management, Activity, Critical path, Decision, Completion time

Posted Date: August 17th, 2021

DOI: https://doi.org/10.21203/rs.3.rs-773840/v1

License: (c) (1) This work is licensed under a Creative Commons Attribution 4.0 International License.

Read Full License 


\section{Abstract}

Recently the smart city concept has become a burning topic in India. The government of India has already selected more than hundred cities to be converted into smart cities. Agartala, the capital of Tripura, is one of such selected cities. There are numerous applications of engineering aspects in the course of conversion of a city into a smart city. Project Management is one such area which has tremendous application in smart city development. But extensive literature reviews show only the concept, various constituents, and effects of a smart city on its citizens. No systematic procedure of implementation of different activities with a view to converting a city into a smart city using the concept of Project Management from nascent stage has been found in literature. Application of Project Management can help a lot the competent authority to get a clear idea on different components of smart city project. The present work highlights the application of Project Management on smart city development. Agartala city has been considered as a case study for this present work due to its typical geographical location as well as different activities it requires to start with. The degree of importance of different activities in the network diagram of the project has been decided by applying multi criteria decision making tools. Thus, this present work finally determines the total project completion time together with critical activities of the project. This work can give rise to a general idea in the competent authorities dealing with other cities also.

\section{Introduction}

\subsection{A glimpse of Agartala}

Agartala, the capital of Tripura, is a landlocked city and a unique type compared to other cities of India in so far geographical location is concerned. A landlocked city means no scope or a little scope through other territories i.e., there is no direct routes which is essential for national trade a cheaper means of transport for goods unlike air routes. In this case, the only one opening of Tripura is Assam- Agartala route which is circuitous in nature and passes through series of hills and forest. The three sides of Tripura is surrounded by the neighboring country, Bangladesh. The major problem arises for import and export business which is essential for any city that wants to develop itself keeping pace with the global trend. Because no city can be self sufficient and national or international trade becomes essential in the context of development. A landlocked city always has to depend on neighboring states. They have no direct access to global market. They lag behind so far as globalization is concerned. Therefore, some extra effort, attention and attitude are required to transform this city into a smart city. Even it may not be feasible to implement all the required activities at a time. Gradual implementation of the activities is suitable for this type of place. The geographical location of the Agartala city is represented in the following map (fig-1). The government of India recently announced that hundred cities of the country will be transformed into smart cities. Adequate attention and efforts obviously are required during the coming few years to upgrade a city to a smart city which needs to encompass different standard parameters to fulfill the conditions of a smart city. Both the union and state government have pivotal role to play as to help make this journey towards a smart city satisfying all conditions as discussed in subsequent stages. 
On the basis of author's real life experience as well as different categories of citizens' opinion, some of the important parameters along with their sub-parameters which are essential for the city are chosen subsequently for computational work of the present study.

\subsection{Literature Review}

The up gradation of many cities to smart cities is going worldwide. There are examples galore in this regard. It is a measure of immense pleasure that necessity of up gradation of many cities in India has been realized as well in the recent past. A systematic literature review has been conducted in the following paragraphs embracing the meaning o smart city, various important dimensions of smart city, works on some project management with a view in implementing it on smart city development, various MCDM tools which has been used on ranking purpose of different alternatives in other areas and useful for ranking of different activities in the present project network.

Public health management, which is an inevitable step in the present pandemic situation, was incorporated in urban planning (Junior et al, 2021). Authors mainly considered the concept of city health management during crisis period like pandemic situation due to COVID-19. Authors also cited the previous epidemic situation in the context of confrontation with such crisis moments on behalf of city management strategies.

A taxonomy tree has been proposed with a view to fighting against COVID-19 (Rahmani et al, 2020). Authors' systematic literature reviews are beneficial to the people for acquiring knowledge about the infectious disease and eventual self protection techniques.

Assessment of living environment deprivation was studied aiming at hotspot formation in megacities in the context of COVID-19 (Das et al 2020). They developed relation between condition of living environment and hotspots of COVID-19.

Many earlier works on smart cities have been reviewed (Reddy and Crutzen, 2017). They mentioned proponents and opponents views on smart cities. They also proposed a 3RC frame work which was Restrictive, Reflective, Rationalistic and Critical schools. This framework critically analyzed different stages of the development of smart city. Finally, they concluded that smart cities differ in various ways from the point of view for which they actually build up. But the issues which were not addressed by the authors are consideration of various parameters of different stages of the development of smart city, strategy on completion of smart city project, minimization of gap between proponents and opponents views on smart cities to reach a common goal etc.

It was stressed on the two things viz. Internet of Things (IOT) and ambidexterity of the firms through alliances for smart city project by Stefano Bresciani et al (2017). They elaborated on the multi dimensional capabilities of Information and Communication Technologies (ICT) including knowledge management as a special mention. But some vital issues might be included like different social and environmental parameters other than digital technology related parameters in connection with smart city, 
sequence of establishment or installation of the different ICT related sub parameters from nascent stage, total project completion time in case of facilitating the parameters discussed here for a city which was converting into a smart city.

The roles of digital data system for various aspects of a smart city were discussed by Karima Kourtit et al (2016). They also analyzed different decision support tools for complex urban management issues. They tried to establish the ability of digital data system for urban management and policy. Some important issues raised in mind from their work like basic parameters of a city which is in nascent stage in the development of a smart city, practical approach of utilizing digital data system particularly, ICT to the different basic criteria of a smart city, other important parameters besides digital data system or ICT etc.

Work on fire site selection in Kathmandu Metropolitan city, Nepal was studied by Pandav Chaudhury et al (2015). They used Analytic Hierarchy Process (AHP). During the selection process, they considered four criteria by group decision making process. But they did not highlight other important issues for the betterment of Kathmandu city. It would be better if they included judgment of the results obtained by using any other MCDM technique other than AHP.

The gap found in the literatures in connection with local policy and politics for smart city mission in India was highlighted by Sarbeswar Praharaj et al (2017). They also addressed the complex planning and governance mechanisms in so far as smart city mission of India is concerned. They recommended for framing a sound smart city policy. Finally, they suggested strongly the integration and coordination among the central, state and municipality level in connection with various project implementation. But it would be an excellent inclusion if the authors made the specific ranking of the hundred Indian cities to be converted into smart cities based on their existing scenario for an in-depth idea of policy framing for each individual city to fulfill the mission.

A case study of a smart city considering city of Zaragoza (Spain) was analyzed by Daniel Belanche et al (2016). They mentioned some beneficial factors of smart cities. They holistically reviewed hard and soft domain of smart cities. Hard domains were infrastructures, transport, mobility and natural resources. Soft domains were culture, social inclusion, economy and welfare.But their research findings were highly specific and mostly related to the soft domain of the smart city. Moreover it comes to the mind thinking the practical scenario regarding sequence of the components, related to the soft or hard domains, to be implemented during conversion of a city into a smart city.

On quality of life through sustainable development was focused by Isa Baud et al (2001). Among various avenues of sustainable development, they stressed on solid waste management system. They performed detailed case studies on three cities viz. Chennai (India), Manila (Philippines) and Lima (Peru). They also discussed alliances like public-private, public community, community private and their significant roles for developing solid waste management system. But the authors did not highlight the other avenues of sustainable development. Their discussion was restricted to only solid waste management system. The three cities chosen for case studies were already developed in many ways. It was not discussed there the right implementation policy particularly when a small town is likely to convert into a smart city. Also, 
among different alliances, they did not comment on a suitable one for a small town or city. Moreover, to find out the suitable one, it is meaningful to determine weights of different alliances to play their roles.

Sustainable food networks in the case of Bristol in UK were studied by Mathew Reed and Daniel Keech (2017). They highlighted the gap between constituents of Internet of Things like Facebook, Twitter etc. and presented potentially of citizen accessible technological offer in so far as sustainable food network for smart city development is concerned. But the other important parameters for smart city development were not highlighted by authors. Also they could find out the sequence of implementation of sustainable food networks for practical purpose. Moreover it can be added 'the project completion time' if any city is willing to implement sustainable food network with a view to converting into a smart city.

Hokou (house hold registration system) in Sanghai city of China was highlighted by Lime Li et al (2010). They analyzed the beneficial effect of hokou system. They elaborately discussed different types of hokou and residence card available at different stages along with their status. The authors strongly recommended for hokou system implementation to make genuine citizenship of a particular municipality or city which in turn, can contribute to the economic growth of the country. But it was not revealed from this work that the type of city which is exactly suitable for the hokou system. Moreover, it requires discussing in detail the steps to implement hokou system to a city from its nascent stage during conversion into a smart city.

Formation of public spaces in urban areas was studied by Christiane Brosius and Tina Schilbach (2016). They addressed two case studies- Delhi and Sanghai. They stressed on the importance and sustainable development in relation to public spaces. But the authors did not focus on action on cities which have already no space or lack of public space. It would be nice if the authors could give an idea on approximate numerical figures like space between two residence or flats in a city, wideness of streets etc in a particular city. It required mentioning the distance of various public utility places like garbage collection point, market place, crematorium, bus depot etc. from the residential area.

Similarly, in 2017, many authors added at least one new dimension in the literature in so far as smart city is concerned. The role of citizens for transforming a city into a smart city was investigated by Anthony Simonofski etal (2017). They stressed on the involvement of citizens to achieve the smart city goal. They categorized citizens as democratic participants, citizens as co-creators and citizens as ICT users. The authors explained a case study designing a framework in connection with citizens' participation in smart cities. Tourism which can play an important role on smart city was enlightened by Romano Fistola etal (2017). They opined that tourism is a driving urban function that can make cities more efficient and attractive based on some government conditions. The improved quality of life in smart cities was focused by Nader Mohamed et al (2017). They mentioned information and communication technologies (ICT) have vital role to achieve the goal of smart city. They elaborately discussed on the Cloud of Things (CoT) and Fog computing in the context of smart cities. 'Smart Region' instead of 'Smart City' was highlighted by Fabrizio Arneodo et al (2017). The authors realized the necessity of development and provision of facilities beyond a particular boundary of a smart city and that is why they mentioned the 
term 'region'. The authors showed a case study of a region in Italy. Smart grid as an integral component of smart city along with other necessary components was focused by Libing Wu et al (2017). They proposed a new scheme which is efficient identify- based encryption scheme with equality test (IBEET) for smart cities. The authors elaborately explained the features and beneficial effects of their model in connection with smart grid for a smart city. The performance of Low-Power Wide Area Networks (LPWANs) which is also called LORA network, fundamental enablers of Internet of Things for smart cities was evaluated by Davide Magrin et al (2017). Urban safety system (U- safety) was developed by Zhe Peng et al (2017). They inferred safety index for urban area from multiple cross-domain urban data. They opined that urban safety information like crime and emergency is important so far as inhabitants and new travelers are concerned.

But it has not been found implementation of project management for smart city development work. Project management has significant role to make the smart city mission successful, smooth and satisfactory to the citizen. Thus, in the present work an in-depth study on smart city development has been done by incorporating project management concept as well as by applying MCDM techniques.

\section{Computational Techniques}

In this section, computations are shown sequentially. The importance of decision making for smart city development work has been highly reflected here. Multi-criteria decision making (MCDM) methods are used in the present study with a view to avoiding conflicting scenario (Abbas Mardani et al 2015; GwoHshiung Tzeng et al 2005; Yang Gao et al 2010; E Loken 2007). Decision making under fuzzy environment have also been used by researchers to achieve the best decision in confusing cases (F.E.Boran et al 2012; Paul and Sarkar 2019; Liao, 2009). Decision making is an inevitable aspect which cannot be bypassed for any sector like social, technical, economic, etc. Without taking a proper decision, some valuable inputs like man, money, material, method etc may get unsuccessful. A new MCDM method under fuzzy environment was proposed for obtaining precise decision. The new method is called fuzzy technique for best-worst analysis. Authors nicely explained all the working steps with case studies (Hussain ei al, 2021). In the present work decision making has importance on selecting the sequence of activities together with predecessor activities which are very much essential in project management implementation. Decision making technique can only select the priority of task to be completed early with compared to other ones in so far as smart city development is concerned. In this work of smart city development, decision makers first opine their views on different activities in connection with priority of implementation. Subsequently decision makers' views have been verified by developing decision making model. A flow chart (Fig. 2) has been shown to highlight decision makers' role and application of decision making process in the context of present work.

\subsection{Different category of Decision Makers}


Decision Makers opinion are required to develop the decision making model with a view to prioritizing the sequence of activities which are involved during project management stage. Since smart city development is related to every citizen residing in the city, it is quite justifiable to accept the opinion from different category of citizens residing in Agartala. For this present case study, decision makers have been selected on the basis of (i) gender-male or female or transgender, (ii) age-kids, adults, teenagers, senior citizens (iii) professions- service, businessman, doctor, engineer, shopkeeper etc. and (iv) geographical boundary - the citizens those are residing in the developed cities in India or abroad with a view to obtaining some advanced and innovative ideas in so far as smart city development is concerned. In this way, it has been attempted to make the decisions uniform and unbiased such that the largest portion of the citizens can be benefitted irrespective of the gender or age or profession etc. Different decision makers have been shown pictorially in the following figure- 3 .

\subsection{Selection of criteria and alternatives}

The above decision makers have played pivotal roles in selecting criteria and alternatives for the present study. The relevant criteria and alternatives which have been selected by the esteemed decision makers are shown in the following table- 1 and table-2 respectively.

Table-1: Criteria selection by decision makers

\begin{tabular}{|lll|}
\hline SI NO & Criteria (Symbol) & Type \\
\hline 1 & Cost of implementation (C1). & Quantitative \\
\hline 2 & Time to finish the work (C2). & Quantitative \\
\hline 3 & Skilled manpower required to accomplish the work (C3). & Quantitative \\
\hline 4 & Public requirement to get the facility soon (C4). & Qualitative \\
\hline 5 & Availability of raw materials essential for a particular job (C5). & Qualitative \\
\hline
\end{tabular}

Table-2: Table-1: Alternatives selection by decision makers 


\begin{tabular}{|c|c|c|}
\hline $\begin{array}{l}\text { SI } \\
\text { NO }\end{array}$ & Alternative (Symbol) & Type \\
\hline 1 & Land Transport (A1) & Transportation facility \\
\hline 2 & Air Transport (A2) & Transportation facility \\
\hline 3 & Rail Transport (A3) & Transportation facility \\
\hline 4 & E-Governance (A4) & $\begin{array}{l}\text { Information technology } \\
\text { services }\end{array}$ \\
\hline 5 & Extension of internet services (A5) & $\begin{array}{l}\text { Information technology } \\
\text { services }\end{array}$ \\
\hline 6 & Social Education (A6) & $\begin{array}{l}\text { Improvement of educational } \\
\text { standard }\end{array}$ \\
\hline 7 & Pre-primary and Primary education (A7) & $\begin{array}{l}\text { Improvement of educational } \\
\text { standard }\end{array}$ \\
\hline 8 & Graduate and post graduate level (A8) & $\begin{array}{l}\text { Improvement of educational } \\
\text { standard }\end{array}$ \\
\hline 9 & Qualitative improvement of hospital services (A9) & Health care services \\
\hline 10 & Food habit and properly balanced diet (10) & Health care services \\
\hline 11 & Increase of CNG driven vehicles (A11) & Pollution free environment \\
\hline 12 & Introduction of bio-diesel driven cars (A12) & Pollution free environment \\
\hline 13 & $\begin{array}{l}\text { Garbage disposal point and use of compacting machines } \\
\text { (A13) }\end{array}$ & Pollution free environment \\
\hline 14 & Aforestation in and around the city (A14) & Pollution free environment \\
\hline 15 & Improvement of sanitation and hygiene (A15) & Public health services \\
\hline 16 & Purified drinking water production and supply (A16) & Public health services \\
\hline 17 & Children's park and play centers (A17) & Entertainment and amenities \\
\hline 18 & Food court and malls (A18) & Entertainment and amenities \\
\hline 19 & Law and order (A19) & Social security for citizens \\
\hline 20 & $\begin{array}{l}24 \times 7 \text { health care centre for senior citizen and emergency } \\
\text { service (A20) }\end{array}$ & Social security for citizens \\
\hline
\end{tabular}

\subsection{Framing of decision matrix}

After deciding the criteria and alternatives by the experts, it is now turn to define fuzzy numbers against each linguistic term. It is because of the fact that linguistic terms have been assigned by the experts for the two qualitative criteria viz public requirement and availability of raw materials. There are articles 
galore in the literature where basics of fuzzy sets and their applications are available (Zadeh 1965; Zadeh $1975 ;$ Klir 1995). Thus, linguistic values and corresponding fuzzy numbers, for the two criteria as mentioned here, have been shown in table-3 and table-4 respectively. Triangular fuzzy number has been used for the present study. Now the decision matrix has been formulated with the both quantitative and qualitative data. Experts from different private and public organizations helped a lot to the decision makers to consider quantitative data for the present study based on their past experience, data storage record and forecasting techniques. For the qualitative criteria, only two decision makers have been selected to avoid complexity of the computational steps. The decision matrix so formed is shown in table- 5 . Table- 6 shows the decision makers' choice with fuzzy numbers for the qualitative criteria. But this table- 6 comprises of both crisp and fuzzy values. It is difficult to solve the decision matrix in its present form. That's why the fuzzy numbers have been converted into crisp values by defuzzification process. The centre of gravity technique of defuzzification process has been applied in this step of conversion. Table-7 shows the crisp values of two qualitative criteria together with the values of quantitative criteria. And thus, the final decision matrix is presented here in table-8, where sum of square and square root have been calculated

Table 3

Linguistic variables for the criteria (C4) values of alternatives

\begin{tabular}{|ll|}
\hline LINGUISTIC VALUES & FUZZY NUMBER \\
\hline Extremely Required(ER) & $(8,9,10)$ \\
\hline Very much Required(VR) & $(7,8,9)$ \\
\hline Moderately Required(MR) & $(6,7,8)$ \\
\hline Required(R) & $(3,5,7)$ \\
\hline Slightly Required(SR) & $(1,3,5)$ \\
\hline Not Required(NR) & $(0,1,3)$ \\
\hline
\end{tabular}


Table 4

Linguistic variables for the criteria (C5) values of alternative

\begin{tabular}{|ll|}
\hline LINGUISTIC VALUES & FUZZY NUMBER \\
\hline Extremely Good(EG) & $(9,10,10)$ \\
Very Good(VG) & $(7,9,10)$ \\
\hline Good(G) & $(5,7,9)$ \\
\hline Fair(F) & $(3,5,7)$ \\
Poor(P) & $(1,3,5)$ \\
Very Poor(VP) & $(0,1,3)$ \\
\hline
\end{tabular}


Table 5

Decision matrix consisting of quantitative and qualitative data

\begin{tabular}{|c|c|c|c|c|c|c|c|}
\hline & \multicolumn{3}{|c|}{ Quantitative Criteria } & \multicolumn{4}{|c|}{ Qualitative Criteria } \\
\hline & $\mathrm{C} 1$ & $\mathrm{C} 2$ & $\mathrm{C} 3$ & $\mathrm{C} 4$ & & C5 & \\
\hline & (Crore) & (Months) & (Total manpower) & DM1 & DM2 & DM1 & DM2 \\
\hline $\mathrm{A} 1$ & 10 & 12 & 500 & ER & VR & VG & G \\
\hline $\mathrm{A} 2$ & 30 & 18 & 400 & MR & VR & $\mathrm{F}$ & $\mathrm{F}$ \\
\hline A3 & 20 & 6 & 450 & VR & MR & $\mathrm{F}$ & $P$ \\
\hline A4 & 5 & 8 & 100 & $\mathrm{R}$ & VR & $P$ & $P$ \\
\hline A5 & 4 & 7 & 150 & VR & VR & $P$ & $P$ \\
\hline A6 & 6 & 10 & 300 & VR & ER & EG & VG \\
\hline A7 & 5 & 15 & 250 & VR & $\mathrm{R}$ & VG & VG \\
\hline A8 & 8 & 18 & 150 & VR & VR & G & G \\
\hline A9 & 15 & 20 & 440 & ER & ER & VP & $P$ \\
\hline A10 & 2 & 5 & 180 & SR & $\mathrm{R}$ & $\mathrm{F}$ & $\mathrm{F}$ \\
\hline A11 & 12 & 16 & 240 & $\mathrm{R}$ & MR & VG & G \\
\hline A12 & 7 & 14 & 180 & SR & MR & VP & $P$ \\
\hline A13 & 3 & 9 & 320 & VR & ER & $\mathrm{P}$ & $P$ \\
\hline A14 & 0.1 & 3 & 160 & MR & VR & EG & EG \\
\hline A15 & 0.5 & 4 & 120 & MR & VR & VG & G \\
\hline A16 & 0.3 & 11 & 50 & VR & VR & VG & G \\
\hline A17 & 0.8 & 8 & 220 & $\mathrm{R}$ & MR & VG & VG \\
\hline A18 & 0.6 & 18 & 270 & NR & SR & VP & $P$ \\
\hline A19 & 0.15 & 10 & 130 & VR & ER & $G$ & $\mathrm{~F}$ \\
\hline A20 & 9 & 14 & 110 & ER & ER & VP & $\mathrm{F}$ \\
\hline
\end{tabular}

Table 6: Decision matrix with fuzzy numbers of qualitative Criteria 


\begin{tabular}{|c|c|c|c|c|c|c|c|}
\hline & \multicolumn{3}{|c|}{ Quantitative Criteria } & \multicolumn{4}{|c|}{ Qualitative Criteria } \\
\hline & \multirow{2}{*}{$\begin{array}{l}\text { C1 } \\
\text { (Crore) }\end{array}$} & \multirow{2}{*}{$\begin{array}{l}\text { C2 } \\
\text { (Months) }\end{array}$} & \multirow{2}{*}{$\begin{array}{l}\text { C3 } \\
\text { (Total manpower) }\end{array}$} & \multicolumn{2}{|l|}{$\mathrm{C} 4$} & \multicolumn{2}{|l|}{ C5 } \\
\hline & & & & DM1 & DM2 & DM1 & DM2 \\
\hline A1 & 10 & 12 & 500 & $(8,9,10)$ & $(7,8,9)$ & $(7,9,10)$ & $(5,7,9)$ \\
\hline A2 & 30 & 18 & 400 & $(6,7,8)$ & $(7,8,9)$ & $(3,5,7)$ & $(3,5,7)$ \\
\hline A3 & 20 & 6 & 450 & $(7,8,9)$ & $(6,7,8)$ & $(3,5,7)$ & $(1,3,5)$ \\
\hline A4 & 5 & 8 & 100 & $(3,5,7)$ & $(7,8,9)$ & $(1,3,5)$ & $(1,3,5)$ \\
\hline A5 & 4 & 7 & 150 & $(7,8,9)$ & $(7,8,9)$ & $(1,3,5)$ & $(1,3,5)$ \\
\hline A6 & 6 & 10 & 300 & $(7,8,9)$ & $(8,9,10)$ & $(9,10,10)$ & $(7,9,10)$ \\
\hline A7 & 5 & 15 & 250 & $(7,8,9)$ & $(3,5,7)$ & $(7,9,10)$ & $(7,9,10)$ \\
\hline A8 & 8 & 18 & 150 & $(7,8,9)$ & $(7,8,9)$ & $(5,7,9)$ & $(5,7,9)$ \\
\hline A9 & 15 & 20 & 440 & $(8,9,10)$ & $(8,9,10)$ & $(0,1,3)$ & $(1,3,5)$ \\
\hline A10 & 2 & 5 & 180 & $(1,3,5)$ & $(3,5,7)$ & $(3,5,7)$ & $(3,5,7)$ \\
\hline A11 & 12 & 16 & 240 & $(3,5,7)$ & $(6,7,8)$ & $(7,9,10)$ & $(5,7,9)$ \\
\hline $\mathrm{A} 12$ & 7 & 14 & 180 & $(1,3,5)$ & $(6,7,8)$ & $(0,1,3)$ & $(1,3,5)$ \\
\hline A13 & 3 & 9 & 320 & $(7,8,9)$ & $(8,9,10)$ & $(1,3,50$ & $(1,3,5)$ \\
\hline A14 & 0.1 & 3 & 160 & $(6,7,8)$ & $(7,8,9)$ & $(9,10,10)$ & $(9,10,10)$ \\
\hline A15 & 0.5 & 4 & 120 & $(6,7,8)$ & $(7,8,9)$ & $(7,9,10)$ & $(5,7,9)$ \\
\hline A16 & 0.3 & 11 & 50 & $(7,8,9)$ & $(7,8,9)$ & $(7,9,10)$ & $(5,7,9)$ \\
\hline A17 & 0.8 & 8 & 220 & $(3,5,7)$ & $(6,7,8)$ & $(7,9,10)$ & $(7,9,10)$ \\
\hline A18 & 0.6 & 18 & 270 & $(0,1,3)$ & $(1,3,5)$ & $(0,1,3)$ & $(1,3,5)$ \\
\hline A19 & 0.15 & 10 & 130 & $(7,8,9)$ & $(8,9,10)$ & $(5,7,9)$ & $(3,5,7)$ \\
\hline A20 & 9 & 14 & 110 & $(8,9,10)$ & $(8,9,10)$ & $(0,1,3)$ & $(3,5,7)$ \\
\hline
\end{tabular}


Table 7

Decision matrix with crisp values of qualitative criteria

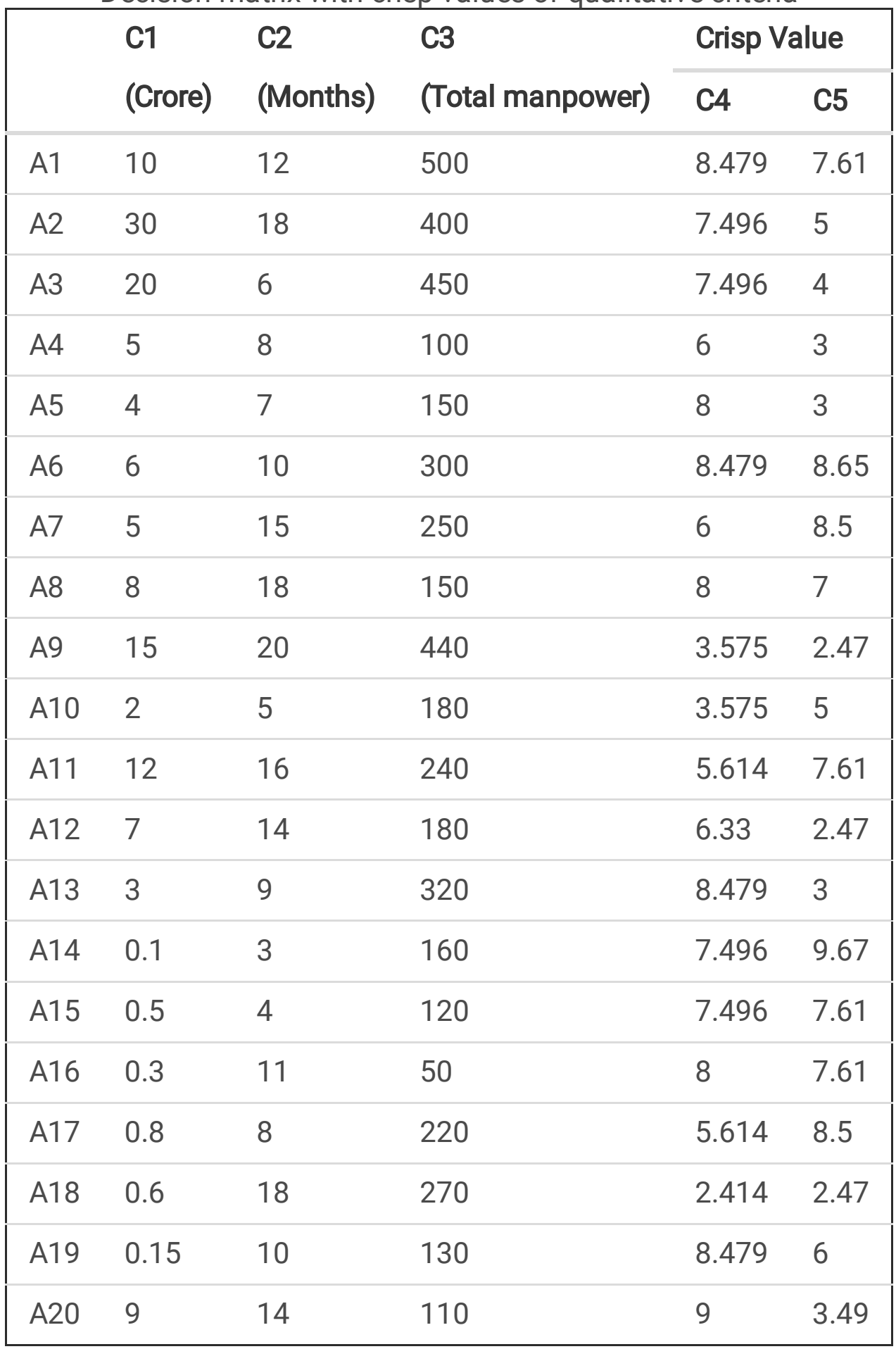

Table-8: Final decision matrix 


\begin{tabular}{|c|c|c|c|c|c|}
\hline & QUANTITII & E DATA & & QUALITATI & E DATA \\
\hline & C1 & & $\mathrm{C} 3$ & $\mathrm{C} 4$ & C5 \\
\hline & (Crore) & (Months) & (Total manpower) & & \\
\hline A1 & 10 & 12 & 500 & 8.479 & 7.61 \\
\hline A2 & 30 & 18 & 400 & 7.496 & 5 \\
\hline A3 & 20 & 6 & 450 & 7.496 & 4 \\
\hline A4 & 5 & 8 & 100 & 6 & 3 \\
\hline A5 & 4 & 7 & 150 & 8 & 3 \\
\hline A6 & 6 & 10 & 300 & 8.479 & 8.65 \\
\hline A7 & 5 & 15 & 250 & 6 & 8.5 \\
\hline A8 & 8 & 18 & 150 & 8 & 7 \\
\hline A9 & 15 & 20 & 440 & 3.575 & 2.47 \\
\hline A10 & 2 & 5 & 180 & 3.575 & 5 \\
\hline A11 & 12 & 16 & 240 & 5.614 & 7.61 \\
\hline A12 & 7 & 14 & 180 & 6.33 & 2.47 \\
\hline A13 & 3 & 9 & 320 & 8.479 & 3 \\
\hline A14 & 0.1 & 3 & 160 & 7.496 & 9.67 \\
\hline A15 & 0.5 & 4 & 120 & 7.496 & 7.61 \\
\hline A16 & 0.3 & 11 & 50 & 8 & 7.61 \\
\hline A17 & 0.8 & 8 & 220 & 5.614 & 8.5 \\
\hline A18 & 0.6 & 18 & 270 & 2.41 & 2.47 \\
\hline A19 & 0.15 & 10 & 130 & 8.479 & 6 \\
\hline A20 & 9 & 14 & 110 & 9 & 3.49 \\
\hline SUM OF SQUARE & 2079.373 & 3054 & 1431200 & 991.8061 & 752.9628 \\
\hline SQRT & 45.600 & 55.260 & 1196.32 & 31.493 & 27.44 \\
\hline
\end{tabular}

2.4 Determination of criteria weight and solution of decision matrix 
Thus the decision matrix has been formulated. It is now required to solve the decision matrix by using any suitable method to get the proper ranking of the alternatives. With a view to solving the decision matrix, TOPSIS method has been applied here, because of its flexibility and simplicity. Different researchers extensively used TOPSIS method in diverse field of engineering, social science and management areas. It has enabled the decision makers to get a proper rank or priority of alternatives in their respective areas (Bakhoum and Brown 2013; Wang and Chang 2007; Yusuf Tansellc2012). The details of the TOPSIS method are furnished in appendix-A.

In this stage it is required to find out the weights of the criteria. For this purpose pair wise comparison matrix has been formulated with the expert opinions. The pair wise comparison matrix has been solved by using AHP technique. In most of the cases AHP has been used to evaluate criteria weights or ranking of alternatives (Saaty 1980; Saaty 1994; Majumdar et al 2004). The details of the AHP method are furnished in appendix-B.

Table 9

Pair wise comparison matrix

\begin{tabular}{|llllllll|}
\hline & C1 & C2 & C3 & C4 & C5 & GM & RW \\
\hline C1 & 1 & 1 & $1 / 2$ & $1 / 3$ & $1 / 5$ & 0.506 & 0.079 \\
C2 & 1 & 1 & $1 / 2$ & $1 / 2$ & $1 / 4$ & 0.574 & 0.090 \\
C3 & 2 & 2 & 1 & $1 / 3$ & $1 / 5$ & 0.768 & 0.120 \\
C4 & 3 & 2 & 3 & 1 & $1 / 3$ & 1.431 & 0.224 \\
C5 & 5 & 4 & 5 & 3 & 1 & 3.129 & 0.488 \\
SUM & 12 & 10 & 10 & 5.167 & 1.983 & $\sum \mathrm{GM}=6.408$ & $\sum \mathrm{RW}=1.000$ \\
\hline
\end{tabular}

$$
\begin{aligned}
& \lambda \mathbb{\boxplus}_{\max }=(12 * 0.079)+(10 * 0.090)+(10 * 0.120)+(5.167 * 0.224)+(1.983 * 0.488)=5.173 \\
& \mathbf{C l}=\left(\nabla_{\max }-\mathrm{n}\right) /(\mathrm{n}-1)=(5.173-5) /(5-1)=0.043 \\
& \mathbf{R} \mathbf{I}=1.98 *(n-2) / n=1.188
\end{aligned}
$$$$
\mathbf{C R}=\mathbf{C l} / \mathbf{R I}=0.043 / 1.188=0.0362=3.62 \% \text {, which is less than } 10 \% \text { and hence acceptable }
$$

Thus, the weights of different criteria are: $[\mathrm{C} 1]^{\mathrm{w}}=0.079,[\mathrm{C} 2]^{\mathrm{W}}=0.090,[\mathrm{C} 3]^{\mathrm{W}}=0.120,[\mathrm{C} 4]^{\mathrm{w}}=0.224$ and $[C 5]^{\mathrm{w}}=0.488$. The final decision matrix obtained earlier has been solved sequentially following TOPSIS methodology and normalized decision matrix, weighted normalized decision matrix, separation distance along with relative closeness have been shown in the table-10 to table-12 respectively. 
Table 10

Normalized decision matrix

\begin{tabular}{|llllll|}
\hline & \multicolumn{2}{l}{ QUANTITIVE DATA } & \multicolumn{2}{l}{ QUALITATIVE DATA } \\
\cline { 2 - 6 } & C1 & C2 & C3 & C4 & C5 \\
\hline A1 & 0.219 & 0.217 & 0418 & 0.269 & 0.277 \\
\hline A2 & 0.658 & 0.326 & 0.334 & 0.238 & 0.181 \\
\hline A3 & 0.439 & 0.109 & 0.376 & 0.238 & 0.146 \\
\hline A4 & 0.110 & 0.145 & 0.084 & 0.190 & 0.109 \\
\hline A5 & 0.008 & 0.127 & 0.125 & 0.254 & 0.109 \\
\hline A6 & 0.132 & 0.181 & 0.251 & 0.269 & 0.315 \\
\hline A7 & 0.110 & 0.271 & 0.209 & 0.190 & 0.310 \\
\hline A8 & 0.175 & 0.326 & 0.125 & 0.254 & 0.255 \\
\hline A9 & 0.329 & 0.362 & 0.368 & 0.113 & 0.090 \\
\hline A10 & 0.044 & 0.090 & 0.150 & 0.113 & 0.182 \\
\hline A11 & 0.263 & 0.290 & 0.201 & 0.178 & 0.277 \\
\hline A12 & 0.154 & 0.253 & 0.150 & 0.201 & 0.090 \\
\hline A13 & 0.066 & 0.163 & 0.267 & 0.269 & 0.109 \\
\hline A14 & 0.002 & 0.050 & 0.134 & 0.238 & 0.352 \\
\hline A15 & 0.011 & 0.072 & 0.100 & 0.238 & 0.277 \\
\hline A16 & 0.007 & 0.199 & 0.042 & 0.254 & 0.277 \\
\hline A17 & 0.018 & 0.145 & 0.184 & 0.178 & 0.310 \\
\hline A18 & 0.013 & 0.326 & 0.226 & 0.077 & 0.090 \\
\hline A19 & 0.003 & 0.181 & 0.109 & 0.269 & 0.219 \\
\hline A20 & 0.197 & 0.253 & 0.092 & 0.286 & 0.127 \\
\hline & & & & & \\
\hline
\end{tabular}


Table 11

Weighted normalized decision matrix

\begin{tabular}{|llllll|}
\hline & \multicolumn{2}{l}{ QUANTITIVE DATA } & \multicolumn{3}{l|}{ QUALITATIVE DATA } \\
\cline { 2 - 6 } & C1 & C2 & C3 & C4 & C5 \\
\hline A1 & 0.017 & 0.020 & 0.0418 & 0.052 & 0.1396 \\
\hline A2 & 0.052 & 0.032 & 0.0334 & 0.046 & 0.0917 \\
\hline A3 & 0.035 & 0.010 & 0.0376 & 0.046 & 0.0736 \\
\hline A4 & 0.009 & 0.014 & 0.0084 & 0.037 & 0.054 \\
\hline A5 & 0.007 & 0.0127 & 0.0125 & 0.0491 & 0.054 \\
\hline A6 & 0.010 & 0.0181 & 0.0251 & 0.052 & 0.159 \\
\hline A7 & 0.009 & 0.0271 & 0.0209 & 0.037 & 0.1563 \\
\hline A8 & 0.014 & 0.0326 & 0.0125 & 0.0491 & 0.1286 \\
\hline A9 & 0.026 & 0.0362 & 0.0368 & 0.0219 & 0.0453 \\
\hline A10 & 0.003 & 0.009 & 0.0150 & 0.0219 & 0.182 \\
\hline A11 & 0.021 & 0.029 & 0.0201 & 0.0344 & 0.1396 \\
\hline A12 & 0.012 & 0.0253 & 0.0150 & 0.039 & 0.0453 \\
\hline A13 & 0.005 & 0.0163 & 0.0267 & 0.052 & 0.0549 \\
\hline A14 & 0.00016 & 0.005 & 0.0134 & 0.046 & 0.1775 \\
\hline A15 & 0.001 & 0.0072 & 0.010 & 0.046 & 0.1396 \\
\hline A16 & 0.0006 & 0.0199 & 0.0042 & 0.0491 & 0.1396 \\
\hline A17 & 0.001 & 0.0145 & 0.0184 & 0.0344 & 0.1563 \\
\hline A18 & 0.001 & 0.0326 & 0.0226 & 0.0149 & 0.0453 \\
\hline A19 & 0.0002 & 0.0181 & 0.0109 & 0.052 & 0.1104 \\
\hline A20 & 0.016 & 0.0253 & 0.0092 & 0.0553 & 0.0640 \\
\hline & & & & & \\
\hline
\end{tabular}

Maximum value for each factor $\left(a^{+}\right):-(0.052,0.0362,0.0418,0.0553,0.182)$

Minimum value for each factor $\left(a^{-}\right):-(0.00016,0.005,0.0042,0.0149,0.0453)$ 
Table 12

Separation distance and relative closeness

\begin{tabular}{|llll|}
\hline \multicolumn{3}{l}{ SEPARATION DISTANCE } & RELATIVE CLOSENESS \\
\hline & Si+ & Si- & Ci \\
\hline A1 & 0.057 & 0.1104 & 0.6595 \\
\hline A2 & 0.091 & 0.086 & 0.4858 \\
\hline A3 & 0.1109 & 0.064 & 0.3659 \\
\hline A4 & 0.142 & 0.0272 & 0.1607 \\
\hline A5 & 0.1409 & 0.043 & 0.2338 \\
\hline A6 & 0.0 .053 & 0.1225 & 0.69800 \\
\hline A7 & 0.058 & 0.1168 & 0.6681 \\
\hline A8 & 0.072 & 0.096 & 0.5714 \\
\hline A9 & 0.143 & 0.0524 & 0.2681 \\
\hline A10 & 0.0705 & 0.1373 & 0.6607 \\
\hline A11 & 0.0609 & 0.1026 & 0.6275 \\
\hline A12 & 0.146 & 0.0353 & 0.1947 \\
\hline A13 & 0.137 & 0.0461 & 0.2517 \\
\hline A14 & 0.062 & 0.1361 & 0.6870 \\
\hline A15 & 0.0796 & 0.0995 & 0.5555 \\
\hline A16 & 0.078 & 0.1014 & 0.5652 \\
\hline A17 & 0.0686 & 0.114 & 0.6243 \\
\hline A18 & 0.1496 & 0.0331 & 0.1811 \\
\hline A19 & 0.0954 & 0.0763 & 0.444 \\
\hline A20 & 0.128 & 0.0516 & 0.2873 \\
\hline
\end{tabular}

Thus the final sequence of alternatives which are of great importance to define predecessor activities and draw the project network diagram is shown in the following table-13. 


\begin{tabular}{|c|c|}
\hline & \\
\hline 1st & A6 \\
\hline 2nd & A14 \\
\hline $3 r d$ & A7 \\
\hline 4th & A10 \\
\hline 5th & A1 \\
\hline 6th & A11 \\
\hline 7th & A17 \\
\hline 8th & A8 \\
\hline 9th & A16 \\
\hline 10th & A15 \\
\hline 11th & A2 \\
\hline $12 \mathrm{tH}$ & A19 \\
\hline 13th & A3 \\
\hline 14th & A20 \\
\hline 15th & A9 \\
\hline 16th & A13 \\
\hline 17 th & A5 \\
\hline 18th & A12 \\
\hline 19th & A18 \\
\hline 20th & A4 \\
\hline
\end{tabular}

\subsection{Implementation of project management}

In this final step, project management has been implemented with a view to finding out different parameters which are essential for the smart city project to start with and to make advancement as well. 
The details of project management are available in any standard text book related to production/operations management. Researchers are also carrying on research on different aspects of project management and many articles are available on literature (Papke shield ey al 2017; Andersen E.S 2016; Liu et al 2019; Clegg et al 2018). But application of project management on smart city project has not been found in the literature. Therefore, the present work of implementation of project management can be beneficial to the smart city planners. Now, for the present case study, the sequence of activities helps to fix predecessor activities which are essential for project network diagram. All the predecessor activities and their details are shown in the following table-14. Now with all the activities the required network diagram has been constructed following the standard norms and shown in fig- 4 . The dotted lines represent the dummy activities. 


\begin{tabular}{|c|c|c|}
\hline $\begin{array}{l}\text { Sequence of } \\
\text { Activity }\end{array}$ & Description & Predecessor activity \\
\hline A6 & Social education & - \\
\hline A14 & Aforestation in and around the city & - \\
\hline A7 & Pre-primary \& primary education & - \\
\hline A10 & Food habit \& properly balanced diet & A6 \\
\hline A1 & Land transport & $\mathrm{A} 10, \mathrm{~A} 14$ \\
\hline A11 & Increase of CNG driven vehicles & A7 \\
\hline A17 & Children's park \& play centers & A14 \\
\hline A8 & Graduates and post graduate levels & A10 \\
\hline A16 & Purified drinking water production \& supply & A1 \\
\hline A15 & Improvement of sanitization \& hygiene & $\mathrm{A} 1$ \\
\hline A2 & Air transport & $\mathrm{A} 1$ \\
\hline A19 & Law \& order & $\mathrm{A} 17, \mathrm{~A} 11$ \\
\hline A3 & Rail transport & $\mathrm{A} 11, \mathrm{~A} 8$ \\
\hline \multirow[t]{2}{*}{$\mathrm{A} 20$} & $24 \times 7$ health care centers for senior citizens \& & A15 \\
\hline & Emergency service & \\
\hline A9 & Qualitative improvement of hospital services & A15 \\
\hline A13 & $\begin{array}{l}\text { Garbage disposal point \& use of compacting } \\
\text { machines }\end{array}$ & $\mathrm{A} 2, \mathrm{~A} 19$ \\
\hline A5 & Extension of internet services & A3 \\
\hline A12 & Introduction of biodiesel driven cars & A3 \\
\hline A18 & Food court \& malls & $\mathrm{A} 20, \mathrm{~A} 5$ \\
\hline A4 & E- governance & $\mathrm{A} 13, \mathrm{~A} 5$ \\
\hline
\end{tabular}

\section{Discussions On Results}

Different categories of decision makers have played their roles in selecting the various alternatives. They have selected the important alternatives which are badly needed for this city. Some of the alternatives may seem as basic alternatives or at very preliminary level but decision makers have selected those considering fulfillment of the basic requirements. Every city has a specialty in terms of their location, 
education, political and social culture. In that sense, some cities are advanced where as some other are lagging behind. To fulfill the advance as well as basic requirements, decision makers selected the twenty alternatives for the Agartala city. Based on interaction to the citizens, decision makers have selected five important criteria as well. They have decided the criteria weightage and this has been verified computationally that criteria weightage are justified. TOPSIS method has given rank of the twenty alternatives and these ranks are very much essential to start different activities individually or simultaneously during implementation of project management. This sequence has also helped to decide the predecessor activity while drawing the network diagram. The complete network diagram gives us the idea about to project completion time and critical path of the project. The project completion time which is 61 months for this case study on Agartala is justified considering the present scenario and facilities available here. The result shows that approximately five years are essential to convert the Agartala city into a smart city incorporating the selected twenty facilities for its citizens. The critical path i.e., A14-A1A16-A3-A5-A18 consists of six activities which require for special care during progress of the project.

\section{Conclusions}

The following conclusions are drawn for the present work.

1. Smart city development is a multidisciplinary area. Engineering plays an important role in many aspects. Smart city development cannot be static phenomenon rater it is a dynamic in nature. It means that as time passes, more and more sophisticated parameters may be included with the existing parameters of the smart city.

2. Every city has special features and it should not be taken similar action for conversion into smart cities for all the cities. Rather it should be based on their present situation and facilities available.

3. For the present case study on 'Agartala' city decision makers have selected twenty alternatives and five criteria. These can be considered as initial or first phase development in a dynamic phenomenon. More alternatives and criteria may come into the picture for subsequent development stages. In the initial stage, most of the alternatives are basic in nature and these should be fulfilled first for the citizen of Agartala. In the subsequent development stages also, the present model is applicable.

4. Multi criteria decision making process has vital role in making priority of task (alternatives) to start with. The sequence or ranking obtained from MCDM method is essential to make network diagram as well as to get the predecessor activity of the network diagram. A proper sequence or priority of task can guide for fruitful efforts for the development. Application of fuzzy sets can avoid dilemma of qualitative criteria.

5. Network diagram shows that it requires approximately five years converting 'Ágartala' city into a smart city. The project completion time is justified since Agartala city is lagging behind from other cities in many aspects and that's why many alternatives (activity) have come into the picture. However, PCT depends on the number of activities considered along with some parallel activities performed. For other cities, which have same mission of conversion into smart cities, input and 
output parameters may be changed but the present model can play a vital role to the smart city planners.

6. The present model can be enriched in future in many aspects. More decision makers may be invited so that alternatives and criteria section will be more genuine, justified and unbiased. Some more MCDM methods may be applied with a view to verifying the ranking of the alternatives in so far as activities of the smart city are concerned. Sensitivity analysis may be performed to check the robustness of the sequence obtained by applying MCDM method.

\section{Declarations}

\section{Acknowledgement}

Author sincerely acknowledges the supports by all the decision makers/stakeholders for their valuable information and feedback upon request on time. This work would not be possible to accomplish without the help of some citizens who acted as decision makers of Agartala city.

\section{Compliance with ethical standards}

\section{Conflict of interest}

The author declares that there is no conflict of interest.

\section{Ethical approval}

All steps performed in the present study involving different decision makers were in accordance with ethical standards of the research guidelines of the institute.

\section{Informed consent}

Informed consent was obtained from all individual participants involved in this study.

\section{Authorship contributions}

Author attempted to contribute in smart city development in logical and scientific sequences which will help the stakeholders during progress of the works, author used MCDM technique to set the sequences and project management concept to calculate development time and critical activities to reach the goal.

\section{Disclosure of potential conflicts of interest}

Author declares that he has no conflict of interest.

\section{Research involving human participants (Ethical approval)}

All procedures performed in studies involving human participants were in accordance with the ethical standards of the institutional and/or national research committee and with the 1964 Helsinki declaration 
and its later amendments or comparable ethical standards.

\section{Informed consent}

Informed consent was obtained from all individual participants included in the study.

\section{Funding}

This work has not received any fund from any sponsoring agency.

\section{References}

1. Andersen, E. S. (2016). Do project managers have different perspectives on project management?. International Journal of Project Management, 34(1), 58-65.

2. Arneodo, F., Castelli, R., \& Botta, D. (2017, June). Towards a "Smart Region" Paradigm: Beyond Smart Cities Borders: Piedmont Region Experience. In 2017 International Conference of Electrical and Electronic Technologies for Automotive (pp. 1-8). IEEE.

3. Bakhoum, E. S., \& Brown, D. C. (2013). A hybrid approach using AHP-TOPSIS-entropy methods for sustainable ranking of structural materials. International Journal of Sustainable Engineering, 6(3), 212-224.

4. Baud, I. S. A., Grafakos, S., Hordijk, M., \& Post, J. (2001). Quality of life and alliances in solid waste management: contributions to urban sustainable development. Cities, 18(1), 3-12.

5. Belanche, D., Casaló, L. V., \&Orús, C. (2016). City attachment and use of urban services: Benefits for smart cities. Cities, 50, 75-81.

6. Boran, F. E., Boran, K. U. R. T. U. L. U. Ş., \& Dizdar, E. (2012). A fuzzy multi criteria decision making to evaluate energy policy based on an information axiom: a case study in Turkey. Energy Sources, Part B: Economics, Planning, and Policy, 7(3), 230-240.

7. Bresciani, S., Ferraris, A., \& Del Giudice, M. (2018). The management of organizational ambidexterity through alliances in a new context of analysis: Internet of Things (IOT) smart city projects. Technological Forecasting and Social Change, 136, 331-338.

8. Brosius, C., \&Schilbach, T. (2016). Introduction: "Mind the Gap": Thinking about in-between spaces in Delhi and Shanghai. City Cult Soc 7 (4): 221-226.

9. Chaudhary, P., Chhetri, S. K., Joshi, K. M., Shrestha, B. M., \& Kayastha, P. (2016). Application of an Analytic Hierarchy Process (AHP) in the GIS interface for suitable fire site selection: A case study from Kathmandu Metropolitan City, Nepal. Socio-Economic Planning Sciences, 53, 60-71.

10. Clegg, S., Killen, C. P., Biesenthal, C., \& Sankaran, S. (2018). Practices, projects and portfolios: Current research trends and new directions. International Journal of Project Management, 36(5), 762-772.

11. Das, A., Ghosh, S., Das, K., Basu, T., Dutta, I., \& Das, M. (2021). Living environment matters: Unravelling the spatial clustering of COVID-19 hotspots in Kolkata megacity, India. Sustainable Cities and Society, 65, 102577. 
12. Fistola, R., Raimondo, M., \& La Rocca, R. A. (2017, June). The smart city and mobility: The functional polarization of urban flow. In 2017 th IEEE International Conference on Models and Technologies for Intelligent Transportation Systems (MT-ITS) (pp. 532-537). IEEE.

13. Gao, Y., Liu, Z., Hu, D., Zhang, L., \& Gu, G. (2010). Selection of green product design scheme based on multi-attribute decision-making method. International Journal of Sustainable Engineering, 3(4), 277291.

14. Hussain, A., Chun, J., \& Khan, M. (2021). A novel multicriteria decision making (MCDM) approach for precise decision making under a fuzzy environment. Soft Computing, 25(7), 5645-5661.

15. İç, Y. T. (2012). An experimental design approach using TOPSIS method for the selection of computer-integrated manufacturing technologies. Robotics and Computer-Integrated Manufacturing, 28(2), 245-256.

16. Junior, C. M., Ribeiro, D. M. N. M., \& Viana, A. B. N. (2021). Public health in times of crisis: An overlooked variable in city management theories?. Sustainable Cities and Society, 66, 102671.

17. Klir, G., \& Yuan, B. (1995). Fuzzy sets and fuzzy logic (Vol. 4). New Jersey: Prentice hall.

18. Kourtit, K., Nijkamp, P., \&Steenbruggen, J. (2017). The significance of digital data systems for smart city policy. Socio-Economic Planning Sciences, 58, 13-21.

19. Kummitha, R. K. R., \&Crutzen, N. (2017). How do we understand smart cities? An evolutionary perspective. Cities, 67, 43-52.

20. Li, L., Li, S. M., \& Chen, Y. (2010). Better city, better life, but for whom?: The hukou and resident card system and the consequential citizenship stratification in Shanghai. City, Culture and Society, 1(3), 145-154.

21. Liang, S., Leng, H., Yuan, Q., \& Yuan, C. (2021). Impact of the COVID-19 pandemic: Insights from vacation rentals in twelve mega cities. Sustainable Cities and Society, 103121.

22. Liao, Y. (2009, June). A novel method for decision making based on triangular fuzzy number. In 2009 Chinese Control and Decision Conference (pp. 4276-4279). IEEE.

23. Liu, F., Chen, Y. W., Yang, J. B., Xu, D. L., \& Liu, W. (2019). Solving multiple-criteria R\&D project selection problems with a data-driven evidential reasoning rule. International Journal of Project Management, 37(1), 87-97.

24. Løken, E. (2007). Use of multicriteria decision analysis methods for energy planning problems. Renewable and sustainable energy reviews, 11(7), 1584-1595.

25. Magrin, D., Centenaro, M., \&Vangelista, L. (2017, May). Performance evaluation of LoRa networks in a smart city scenario. In 2017 IEEE International Conference on communications (ICC) (pp. 1-7). ieee.

26. Majumdar, A., Sarkar, B., \& Majumdar, P. K. (2004). Application of analytic hierarchy process for the selection of cotton fibers. fibers and polymers, 5(4), 297-302.

27. Mardani, A., Jusoh, A., Nor, K., Khalifah, Z., Zakwan, N., \& Valipour, A. (2015). Multiple criteria decision-making techniques and their applications-a review of the literature from 2000 to 2014. Economic research-Ekonomskaistraživanja, 28(1), 516-571. 
28. Mohamed, N., Al-Jaroodi, J., Jawhar, I., Lazarova-Molnar, S., \& Mahmoud, S. (2017). SmartCityWare: A service-oriented middleware for cloud and fog enabled smart city services. leee Access, 5, 1757617588.

29. Papke-Shields, K. E., \& Boyer-Wright, K. M. (2017). Strategic planning characteristics applied to project management. International Journal of Project Management, 35(2), 169-179.

30. Paul, S., \& Sarkar, B. (2020). An exploratory analysis of biofuel under the utopian environment. Fuel, 262, 116508.

31. Peng, Z., Xiao, B., Yao, Y., Guan, J., \& Yang, F. (2017, May). U-safety: Urban safety analysis in a smart city. In 2017 IEEE International Conference on Communications (ICC) (pp. 1-6). IEEE.

32. Praharaj, S., Han, J. H., \& Hawken, S. (2018). Towards the right model of smart city governance in India. Sustainable Development Studies, 1.

33. Pujol, F. A., Mora, H., \&Pertegal, M. L. (2019). A soft computing approach to violence detection in social media for smart cities. Soft Computing, 1-11.

34. Rahmani, A. M., \&Mirmahaleh, S. Y. H. (2020). Coronavirus disease (COVID-19) prevention and treatment methods and effective parameters: A systematic literature review. Sustainable cities and society, 102568.

35. Reed, M., \& Keech, D. (2019). Making the city smart from the grassroots up: The sustainable food networks of Bristol. City, Culture and Society, 16, 45-51.

36. Saaty, T. L. (1994). How to make a decision: the analytic hierarchy process. Interfaces, 24(6), 19-43.

37. Saaty, T. L. The Analytic Hierarchy Process,(1980), McGraw-Hill, New York.

38. Simonofski, A., Asensio, E. S., De Smedt, J., \&Snoeck, M. (2017, July). Citizen participation in smart cities: Evaluation framework proposal. In 2017 IEEE 19th conference on business informatics (CBI) (Vol. 1, pp. 227-236). IEEE.

39. Tzeng, G. H., Lin, C. W., \&Opricovic, S. (2005). Multi-criteria analysis of alternative-fuel buses for public transportation. Energy policy, 33(11), 1373-1383.

40. Wang, T. C., \& Chang, T. H. (2007). Application of TOPSIS in evaluating initial training aircraft under a fuzzy environment. Expert Systems with Applications, 33(4), 870-880.

41. Wu, L., Zhang, Y., Choo, K. K. R., \& He, D. (2017). Efficient identity-based encryption scheme with equality test in smart city. IEEE Transactions on Sustainable Computing, 3(1), 44-55.

42. Zadeh, L. A. (1975). The concept of a linguistic variable and its application to approximate reasoning -I. Information sciences, 8(3), 199-249.

43. Zadeh, L. A. (1996). Fuzzy sets. In Fuzzy sets, fuzzy logic, and fuzzy systems: selected papers by Lotfi A Zadeh (pp. 394-432).

\section{Figures}




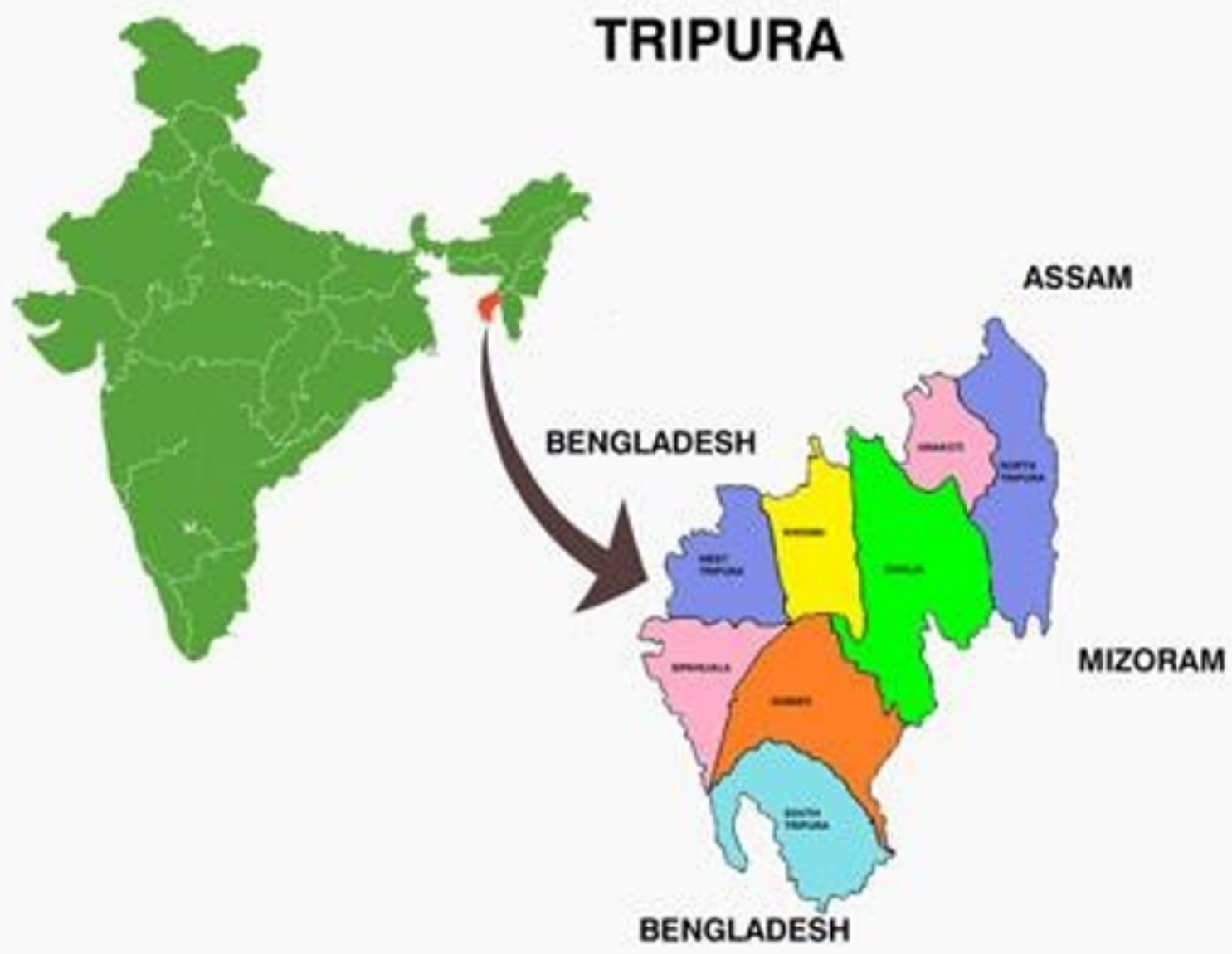

Figure 1

TRIPURA: its location and position 
City: Case study for a smart city

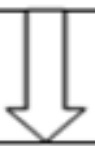

Selection of important parameters and subparameters

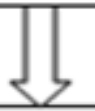

Views of decision makers in connection with priority of implementation

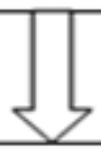

Establish Decision making model to select sequence of activities

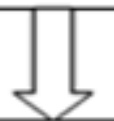

Construction of project network diagram with the selected sequence of activities<smiles>CC1CCCCC1</smiles>

Determination of different aspects of project management like PCT, Critical path etc.

Figure 2

Flow chart of the present work 


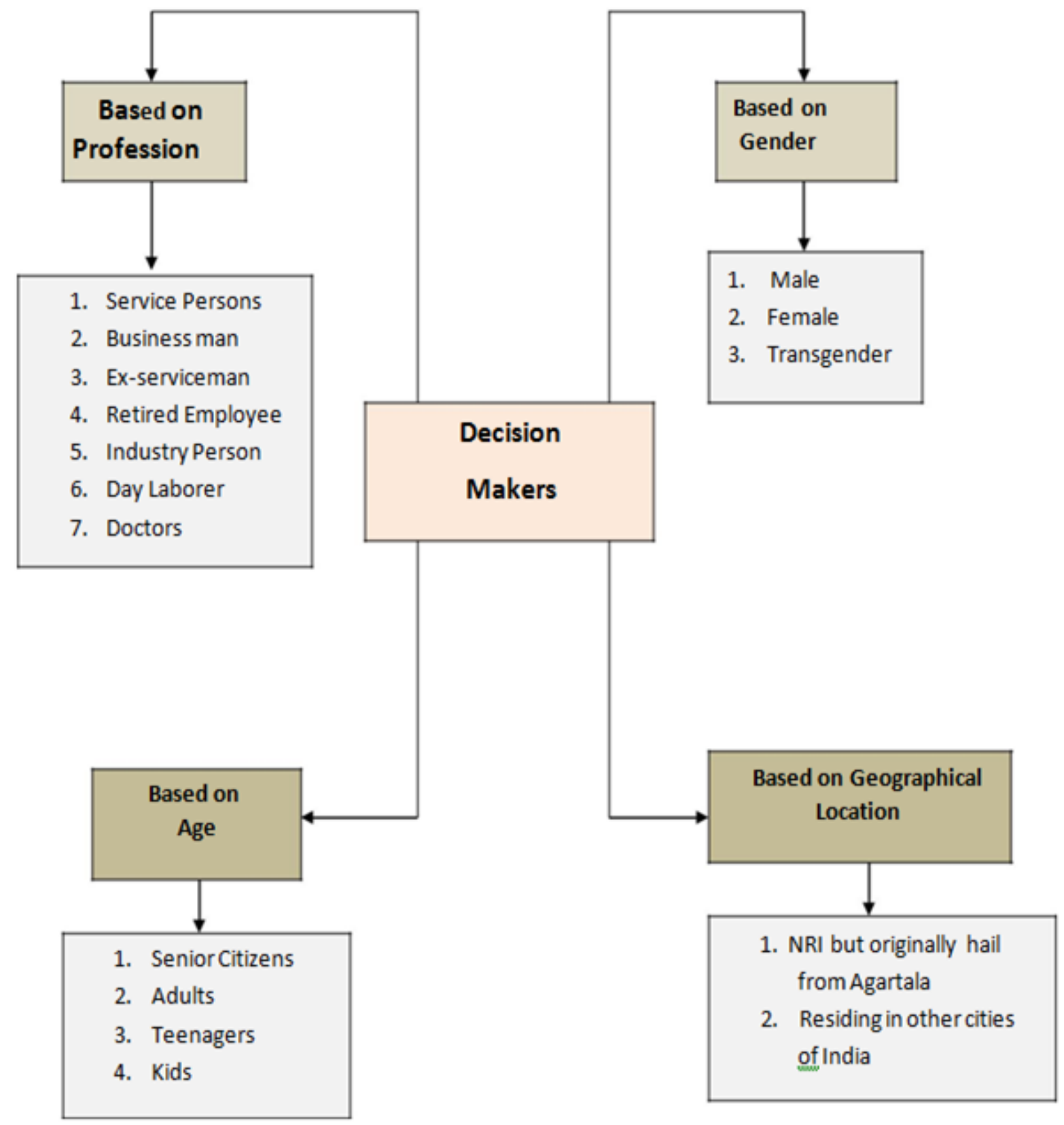

Figure 3

Categorization of Decision Makers 


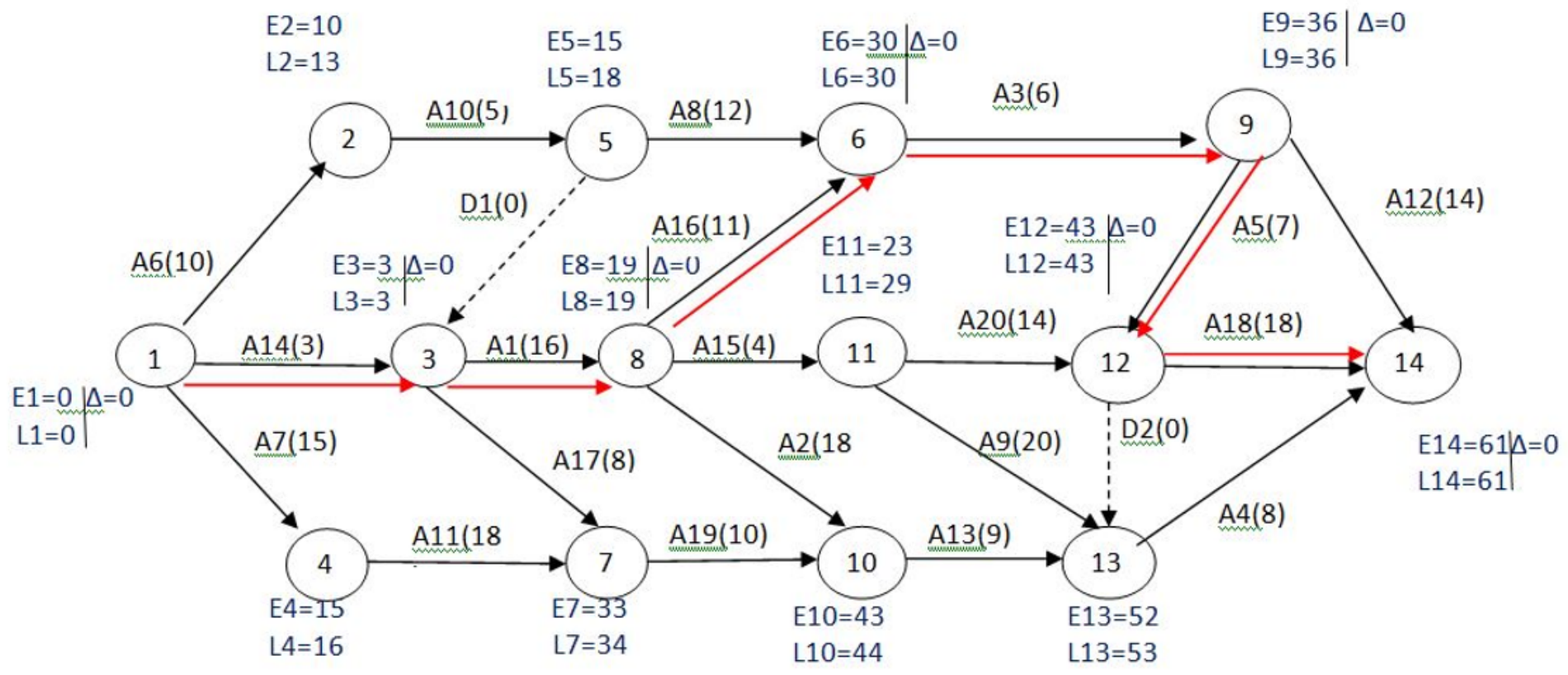

Figure 4

Project network diagram

\section{Supplementary Files}

This is a list of supplementary files associated with this preprint. Click to download.

- Appendix.docx 